\title{
Formoterol May Activate Rat Muscle Regeneration During Cancer Cachexia
}

Elisabet Ametller ${ }^{1}$, PhD; Sílvia Busquets ${ }^{1,2}$, PhD; Gemma Fuster ${ }^{1}$, PhD; Maria T. Figueras $^{1}$, PhD; Mireia Olivan ${ }^{1}$, PhD; Cibely Cristine Fontes de Oliveira ${ }^{1}$, MSc; Josep M. Argilés ${ }^{1,2}$ PhD; and Francisco J. López-Soriano ${ }^{1,2} *$, PhD.

${ }^{1}$ Cancer Research Group, Departament de Bioquímica i Biologia Molecular, Facultat de Biologia, Universitat de Barcelona, Diagonal 645, Barcelona 08028, Spain

${ }^{2}$ Institut de Biomedicina de la Universitat de Barcelona (IBUB), Barcelona, Spain

* Author to whom correspondence should be addressed; Dr. Francisco J. López-Soriano, Cancer Research Group, Departament de Bioquímica i Biologia Molecular, Facultat de Biologia, Universitat de Barcelona, Diagonal 645, 08028-Barcelona, Spain. Telephone: 34934034605 / telefax: 34-934021559 / e-mail: flopez@ub.edu

Received: 08 October 2010 / Accepted: 17 December 2010 / Published: 02 January 2011

\begin{abstract}
PURPOSE: The development of cancer cachexia is the most common manifestation of advanced malignant disease. METHOD: The effects on muscle regeneration of $\beta 2$-adrenoceptor agonist formoterol $(0.3 \mathrm{mg} / \mathrm{kg})$ were tested in cachectic tumour-bearing rats (Yoshida AH-130 ascites hepatoma). RESULTS: Administration of formoterol results in a significant increase in the mass and protein content of tibialis muscle in tumour-bearing-rats. This increase is associated with a decreased myogenin mRNA content together with an increased Pax-7 gene expression. Bupivacaine treatment by local injection results in an important reduction in tibialis weight together with significant increases in Pax-7, myogenin and MyoD gene expression. Formoterol treatment in bupivacaine-treated rats results in significant increases in Pax-7 together with significant decreases in myogenin mRNA content, suggesting that this $\beta 2$-agonist is favouring muscle regeneration by stimulating the proliferation of satellite cells. Altogether, the data reinforce the potential role of formoterol in the treatment of muscle wasting diseases.
\end{abstract}

Keywords: formoterol, skeletal muscle, cachexia, regeneration, bupivacaine, proliferation cells, wasting. 


\section{Introduction:}

The development of cancer cachexia is the most common manifestation of advanced malignant disease. Cachexia occurs in the majority of cancer patients before death, and it is responsible for the death of $22 \%$ of cancer patients ${ }^{1}$. The abnormalities associated with cancer cachexia include anorexia, weight loss, muscle loss and atrophy, anaemia and alterations in carbohydrate, lipid and protein metabolism ${ }^{2}$. The degree of cachexia is inversely correlated with the survival time of the patient and it always implies a poor prognosis ${ }^{3-5}$. Asthenia is one of the most relevant characteristics of cachexia, which reflects the important muscle wasting that takes place in the cachectic cancer patient ${ }^{6}$. Lean body mass depletion is one of the main trends of cachexia and it involves not only skeletal muscle but it also affects cardiac proteins, resulting in important alterations in heart performance. In addition to the increased muscle protein degradation found during cancer growth, the presence of the tumour also induces an increased rate of DNA fragmentation in skeletal muscle in both rats and mice ${ }^{7}$.

$\beta 2$-adrenergic agonists are potent muscle growth promoters in many animal species ${ }^{8,9}$, resulting in skeletal muscle hypertrophy ${ }^{10-13}$, while they cause a reduction of the body fat content ${ }^{14,15}$. These compositional alterations are associated with a redistribution of energy substrates, which are mobilized from storage sites for utilization by tissues such as muscle and brown adipose tissue ${ }^{14}$. The intimate mechanisms by which these compounds exert such effects at the cellular level are still uncertain ${ }^{9,14,15}$, although changes in protein turnover are clearly involved ${ }^{16}$. The large number of physiological functions controlled by $\beta$-adrenergic receptors suggests that the mechanism(s) for the observed changes in carcass composition may be extremely complex. Any proposed mechanism must begin with the possibility of direct effects of the agonist on skeletal muscle and adipocyte $\beta$-adrenergic receptors. Formoterol is one of these compounds with important anti-cachectic effects in animal models. The model of action of this drug is based on its ability to prevent muscle wasting by inhibiting proteolysis in skeletal muscle. Thus, this $\beta 2$-agonist is able to decrease the activation of the ubiquitin-dependent proteolytic system, the main mechanism activated in muscle wasting conditions ${ }^{17}$. Interestingly, in addition to its anti-proteolytic effects, formoterol also decreases muscle apoptosis in muscle-wasting animals ${ }^{17}$. Formoterol is a highly potent, $\beta_{2^{-}}$ adrenoceptor-selective agonist combining the clinical advantages of rapid onset of action with duration of action. This compound is already in use in humans for the treatment of bronchospasm associated with asthma. In vitro, formoterol is a potent airway smooth muscle relaxant with high efficacy, and very high affinity and selectivity for the $\beta_{2}$-adrenoceptor ${ }^{18}$. Moreover, formoterol relaxes bronchial smooth muscle and also provides important clinical benefits in symptomatic patients with chronic obstructive pulmonary disease (COPD) ${ }^{19}$.

After an injury within the muscle, there is an effective restoration of its structure and function ${ }^{20}$. This is possible due to existence of a population of mononuclear acquired myogenic precursors, known as satellite cells ${ }^{21}$. These cells in adult muscle are in quiescent phase $^{22}$. With the appropriate environmental signals, there is an activation of them and they 
become precursors for the formation of new muscles during growth or to repair muscle after an injury ${ }^{23}$. Morphological analysis revealed that during the process of muscle damage an interstitial edema formed by neutrophils is generated. These cells release tropic factors, which activate the satellite cells. This process is accompanied by an inflammatory response ${ }^{24}$. Once activated, these cells ${ }^{25}$ re-enter the cell cycle where they proliferate becoming myoblasts. Following this phase, there is a period of differentiation and the resulting myotubes form a layer of small centronuclear myotubes ${ }^{24}$. The entire process ends 2 weeks after the damage generated, thus obtaining the restoration of cell architecture ${ }^{26}$.

$\beta 2$-adrenergic agonists increase the ability of skeletal muscle repair after injury ${ }^{25,27-31}$. Thus, several studies support the fact that $\beta 2$-adrenergic agonists improve muscle status following bupivacaine injury ${ }^{32}$. Bearing all this in mind, the aim of the present investigation has been to investigate if formoterol, in addition to its antiapoptotic properties, could also be involved in satellite cell proliferation and muscle cell regeneration. In order to accomplish these objectives, we used two different experimental approaches: muscle-wasting tumourbearing animals and bupivacaine-treated animals. Bupivacaine generates muscle damage and induces muscle regeneration ${ }^{33}$.

\section{Results and Discussion:}

\subsection{Effect of formoterol on the muscle regeneration in tumour-bearing rats}

As a result of tumour growth, tibialis muscle weight is significantly decreased (Table 1). As can be seen in the same table, formoterol treatment increased the tibialis weight in tumourbearing rats $(10 \%)$. This increase was associated with an increase in protein content $(40 \%)$. Previous studies from our laboratory have shown that the increase in muscle mass promoted by formoterol is based on: a) activation of protein synthesis, b) inhibition of enhanced protein degradation, and c) inhibition of muscle apoptosis ${ }^{17}$.

Different molecules involved in the process of muscle regeneration and in the regulation of satellite cells, such as Pax7, MyoD and myogenin ${ }^{21}$, are known. In adult skeletal muscle, Pax7 is expressed in the majority of quiescent satellite cells. These cells, when activated, coexpress Pax7 and MyoD 28, 34, 35. When they proliferate, the levels of Pax 7 decrease and other molecules involved in differentiation (such as myogenin) increase their expression. There is a part of the proliferating population that maintains the levels of Pax 7, but not of MyoD, which returns to their state of quiescence ${ }^{34-36}$. Thus, as shown in Table 1 tumour burden actually decreases Pax-7, MyoD and myogenin mRNA expression. In these animals there is a decrease in cyclin D (associated with proliferation) and also of calcineurin (marker of differentiation) protein expression. These results suggest that the mechanisms of regeneration in tumourbearing animals could be blocked. Interestingly, treatment with formoterol in tumour-bearing animals significantly increases Pax-7 (139\%), therefore suggesting a stimulation of myoblast proliferation, and it significantly decreases myogenin (35\%), these results suggesting that the 
$\beta 2$-agonist is potentiating muscle regeneration by activation of the satellite cell population. When protein markers are considered (Table 1), formoterol treatment to control rats clearly promotes a differentiation pattern with significant decreases in cyclin D (35\%) and MyoD (44\%), whereas the $\beta 2$-agonist induces a significant increase in calcineurin (39\%).

During the regeneration process, calcineurin activity can promote transcription factors such as myogenin, thus controlling the satellite cell differentiation and maturation of myotubes ${ }^{37}$. In tumour-bearing rats, similar tendencies in the content of these proteins were observed, although the differences did not reach statistical differences for all the markers. These results suggest that formoterol may activate regenerative mechanisms that are blocked in animals bearing the tumour.

Therefore we decide to study whether the effects of formoterol were direct on muscle cells. Bearing this in mind, we performed $\mathrm{C} 2 \mathrm{C} 12$ myoblast cell cultures, the results being depicted in Figure 1A.

The results obtained confirmed the in vivo observation since formoterol at $0,1 \mu \mathrm{M}$ concentration increased Pax-7 gene expression by 3-fold and decreased myogenin mRNA content by $59 \%$, with no changes in MyoD mRNA content and protein content. Interestingly, the decrease of myogenin is associated with a decrease of calcineurin protein content, therefore suggesting a decreased differentiation and an increased proliferation. These in vitro results were confirmed by protein content measurements (Figure 1B) and direct measurement of the rate of cell proliferation using tritiated thymidine (Figure 1C). It can be seen how formoterol stimulated proliferation in vitro, this coinciding with previous results obtained using $\beta_{2}$-agonists ${ }^{38}$.

Studies by Roberts and McGeachie in a model of muscle regeneration, suggest that $\beta 2$ agonist can have an effect on muscle regeneration by affecting the proliferation of satellite cells ${ }^{27,29}$. The results presented here clearly show that, in addition to the commented effects of formoterol on muscle metabolism, the $\beta 2$-agonist also increases muscle regeneration, participating in the stimulation of muscle satellite cell proliferation when this is inhibited (tumour burden). 
Figure 1. Effects of formoterol on the proliferation, protein content and regeneration markers on $\mathrm{C} 2 \mathrm{C} 12$ cells.

For more details see the Material and Methods section. Results are expressed as percentage of controls (non-treated cells). The minimum number of observations was 6 .

Panel A: Regenerative markers. 1: Pax-7 mRNA content; 2: MyoD mRNA content; 3: Myogenin mRNA content; 4: calcineurin protein content.

Panel B: Protein content. C: control, F: formoterol-treated cells $(0,1 \mu \mathrm{M})$.

Panel C: Proliferation. C: control, F: formoterol-treated cells $(0,1 \mu \mathrm{M})$.

Values that are significantly different by the Student's t-test from the control group are indicated by $* \mathrm{p}<0.05, * * \mathrm{p}<0.01, * * * \mathrm{p}<0.001$.

FIGURE 1

A.

B.

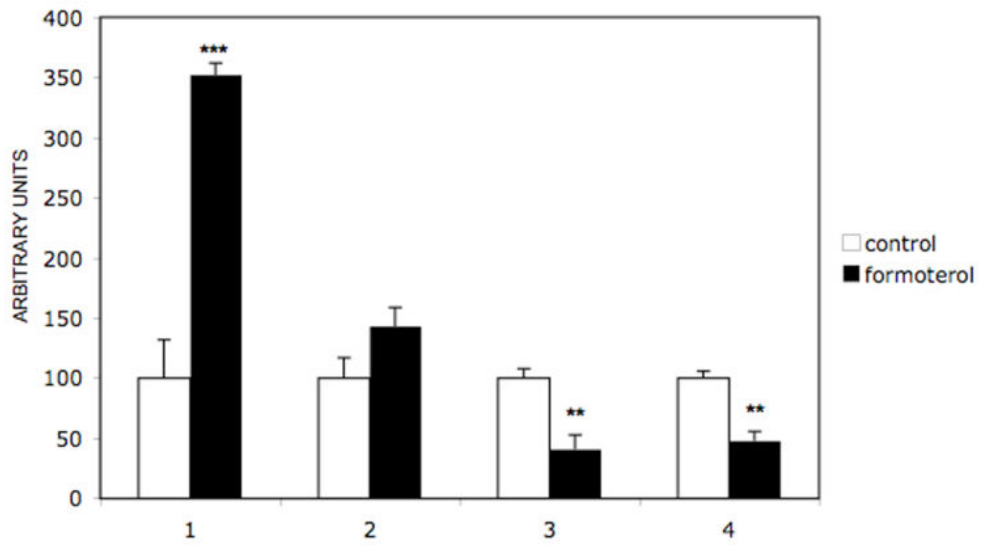

C.
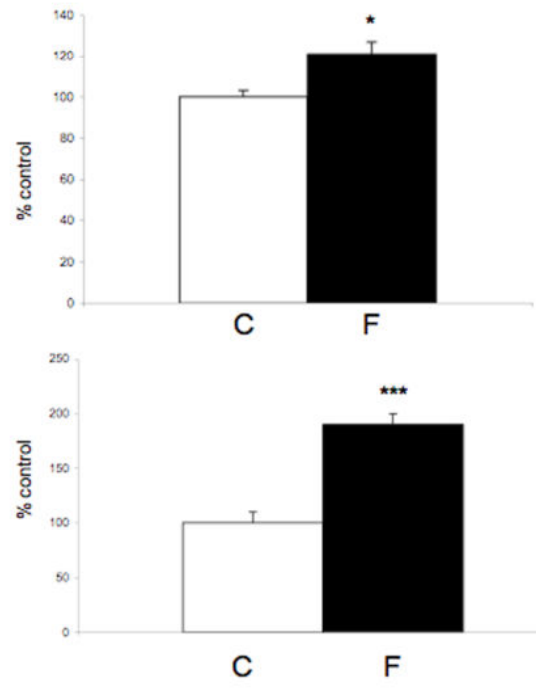
Table 1. Effects of formoterol on tibialis muscle egeneration in tumour-bearing rats.

\section{Treatment}

\begin{tabular}{|c|c|c|c|c|c|}
\hline & \multicolumn{2}{|c|}{ None } & \multicolumn{3}{|c|}{ Formoterol } \\
\hline & $\bar{C}$ & TB & $\bar{C}$ & TB & \\
\hline \multicolumn{6}{|l|}{ Parameters } \\
\hline Muscle weight & $216 \pm 2$ & $163 \pm 5^{* * *}$ & $232 \pm 5 \dagger$ & $179 \pm 5 t^{* * *}$ & ** \\
\hline Protein content & $223 \pm 15$ & $182 \pm 10$ * & $254 \pm 10$ & $254 \pm 14 \dagger$ & †† \\
\hline \multicolumn{6}{|l|}{ Markers } \\
\hline \multicolumn{6}{|l|}{$m R N A$} \\
\hline Pax-7 & $100 \pm 10$ & $61 \pm 12$ * & $134 \pm 24$ & $146 \pm 21$ & $\dagger$ \\
\hline MyoD & $100 \pm 5$ & $83 \pm 5 *$ & $93 \pm 14$ & $79 \pm 9$ & \\
\hline Myogenin & $100 \pm 5$ & $76 \pm 9 *$ & $87 \pm 13$ & $49 \pm 6$ & $t^{*}$ \\
\hline \multicolumn{6}{|l|}{ Protein } \\
\hline MyoD & $100 \pm 7$ & $73 \pm 9 *$ & $65 \pm 8 \dagger$ & $58 \pm 5$ & \\
\hline Cyclin D & $100 \pm 3$ & $79 \pm 7$ * & $56 \pm 12 †$ & $49 \pm 5$ & $\dagger$ \\
\hline Calcineurin & $100 \pm 6$ & $84 \pm 10$ & $139 \pm 10$ & $90 \pm 5$ * & $* *$ \\
\hline
\end{tabular}

For more details see the Material and Methods section. Results are mean \pm S.E.M. for 6 animals. The weight of the tibialis muscle is expressed in $\mathrm{mg} / 100 \mathrm{~g}$ of initial weight of rats. The protein content is expressed in $\mathrm{mg}$ protein / $\mathrm{g}$ tibialis. The data (densitometric units) of both markers as protein and mRNA are represented as the percentage compared to control group (non-treated animal). C: control, TB: tumour-bearing animals. Values that are significantly different by the Student's t-test from the control group are indicated by $* \mathrm{p}<0.05, * * \mathrm{p}<0.01$, $* * * \mathrm{p}<0.001$. Values that are significantly different by the Student's t-test from the formoterol-treated group are indicated by $\dagger \mathrm{p}<0.05, \dagger \dagger \mathrm{p}<0.01, \dagger \dagger \uparrow \mathrm{p}<0.001$.

\subsection{Molecular characterization of a model of muscle regeneration}

Bearing the results obtained in formoterol-treated tumour-bearing animals in mind, we decided to examine if formoterol would also stimulate muscle regeneration in other very well 
characterized muscle damage situations, not involving a pathological state such as cancer, to see if formoterol was also able to influence muscle regeneration. We then investigated the effects of a local bupivacaine injection on muscle growth and differentiation. The anaesthetic bupivacaine is a potent and specific myotoxic agent ${ }^{33,39}$. Local injection of the drug into small skeletal muscles of rat or mouse precipitates an immediate and massive myonecrosis 40 followed by phagocytosis of necrotic debris ${ }^{41}$ and a rapid and apparently complete regeneration of muscle fibres 3-4 weeks after injection ${ }^{39,42}$.

As can be seen in Table 2, seven days of the single bupivacaine injection, there was a significant decrease both in weight and protein content of tibialis muscle $(13 \%$ and $15 \%$ respectively).

Table 2. Effects of bupivacaine on tibialis muscle in Wistar rats

Treatment

None Bupivacaine

\begin{tabular}{|c|c|c|c|c|}
\hline & Day 7 & Day 14 & Day 7 & Day 14 \\
\hline \multicolumn{5}{|l|}{ Parameters } \\
\hline Weight & $217 \pm 3$ & $249 \pm 5 \quad$ ** & $188 \pm 3 \mathrm{tt \dagger}$ & $265 \pm 4 t^{* * *}$ \\
\hline Protein content & $280 \pm 12$ & $216 \pm 7^{* *}$ & $238 \pm 10 †$ & $263 \pm 17 \dagger$ \\
\hline \multicolumn{5}{|l|}{ Markers } \\
\hline \multicolumn{5}{|l|}{$m R N A$} \\
\hline Pax-7 & $100 \pm 7$ & $208 \pm 24 * *$ & $180 \pm 6$ & $301 \pm 27 \dagger^{*}$ \\
\hline MyoD & $100 \pm 13$ & $89 \pm 5$ & $246 \pm 8$ & $116 \pm 25^{* *}$ \\
\hline Myogenin & $100 \pm 5$ & $91 \pm 14$ & $157 \pm 8$ & $270 \pm 11$ tt† *** \\
\hline \multicolumn{5}{|l|}{ Protein } \\
\hline MyoD & $100 \pm 10$ & $100 \pm 14$ & $133 \pm 14$ & $114 \pm 10$ \\
\hline Cyclin D & $100 \pm 14$ & $100 \pm 8$ & $152 \pm 5 \dagger$ & $47 \pm 8 \quad$ †七 $^{* * *}$ \\
\hline Calcineurin & $100 \pm 16$ & $100 \pm 9$ & $178 \pm 19 \dagger$ & $120 \pm 10$ * \\
\hline
\end{tabular}


For more details see the Material and Methods section. Results are mean \pm S.E.M. for 6 animals. The weight of the tibialis muscle is expressed in $\mathrm{mg} / 100 \mathrm{~g}$ of initial weight of rats. The protein content is expressed in $\mathrm{mg}$ protein / $\mathrm{g}$ tibialis. The data (densitometric units) of both markers as protein and mRNA are represented as the percentage compared to control group (non-treated animals at day 7). Day 7: 7 days after the bupivacaine injection; Day 14: 14 days after the bupivacaine injection. Values that are significantly different by the Student's t-test from day 7 group are indicated by $* \mathrm{p}<0.05, * * \mathrm{p}<0.01, * * * \mathrm{p}<0.001$. Values that are significantly different by the Student's t-test from the bupivacaine-treated group are indicated by $\uparrow \mathrm{p}<0.05, \uparrow \dagger \mathrm{p}<0.01, \dagger \dagger \dagger$ $\mathrm{p}<0.001$.

14 days after the induction of muscle damage, the weight of the tibialis muscle recovered and reached values similar to those found in the control group. Recovery is possible because the bupivacaine does not affect elements that are involved in the mechanisms of muscle regeneration, such as basal lamina, vascular supply, nerves and intravenous population of

satellite cells ${ }^{33}$. These changes, seven days after the single bupivacaine injection, are associated with significant increases in Pax $7, \mathrm{MyoD}$ and myogenin mRNA content $(80 \%$, $146 \%$ and $57 \%$ respectively), suggesting an increased rate of myoblast proliferation and differentiation. At day 14 after the bupivacaine injection, the increase in Pax-7 still persists $(45 \%)$, while the increase in myogenin is much more pronounced (197\%) suggesting enhanced differentiation (Table 2). Similar results are observed when protein markers are considered: at day 7 there are increases in MyoD (33\%), cyclin D (52\%) and calcineurin $(78 \%)$, whereas at day 14 there is a significant decrease in cyclin D protein content $(53 \%)$ while the increase in calcineurin still persists $(20 \%)$ suggesting that at this time period there is an increased differentiation and a decreased proliferation (Table 2). From this point of view, the lack of changes in MyoD mRNA suggests a decreased proliferation. These results are consistent with those described by other authors since the chronology of events that occur after treatment with bupivacaine is well known ${ }^{33,42}$.

\subsection{Effects of formoterol in a model of muscle regeneration in tumour-bearing rats}

Taking the changes promoted by bupivacaine induced muscle damage, we decided to investigate if formoterol could be beneficial in restoring muscle damage similar as what happens in a pathological state such cancer. Indeed, as can be seen in Table 3, formoteroltreated rats at day 14 of bupivacaine injection, clearly have an increase of tibialis weight both in control and tumour-bearing animals (15\% and $20 \%$ respectively). In fact, this increase in tibialis weight in the tumour-bearing group was also associated with increases in both protein and DNA content (26\% and $81 \%$ respectively). Pax- 7 mRNA content was also significantly increased by formoterol treatment both in control (140\%) and tumour-bearing rats $(30 \%)$ in bupivacaine-treated group, while no changes were observed in MyoD gene expression as a result of the $\beta 2$-agonist treatment. Conversely, myogenin mRNA content was significantly decreased by formoterol both in control (25\%), and tumour-bearing (40\%) animals bupivacain-treated (Table 3). 
These changes suggest that formoterol treatment influences muscle regeneration. The increase in calcineurin protein content together with the decrease in cyclin D reinforce this idea and suggest the maintenance of the proliferation of satellite cells.

Table 3. Effects of formoterol on tibialis muscle regeneration in bupivacaine-treated tumourbearing rats.

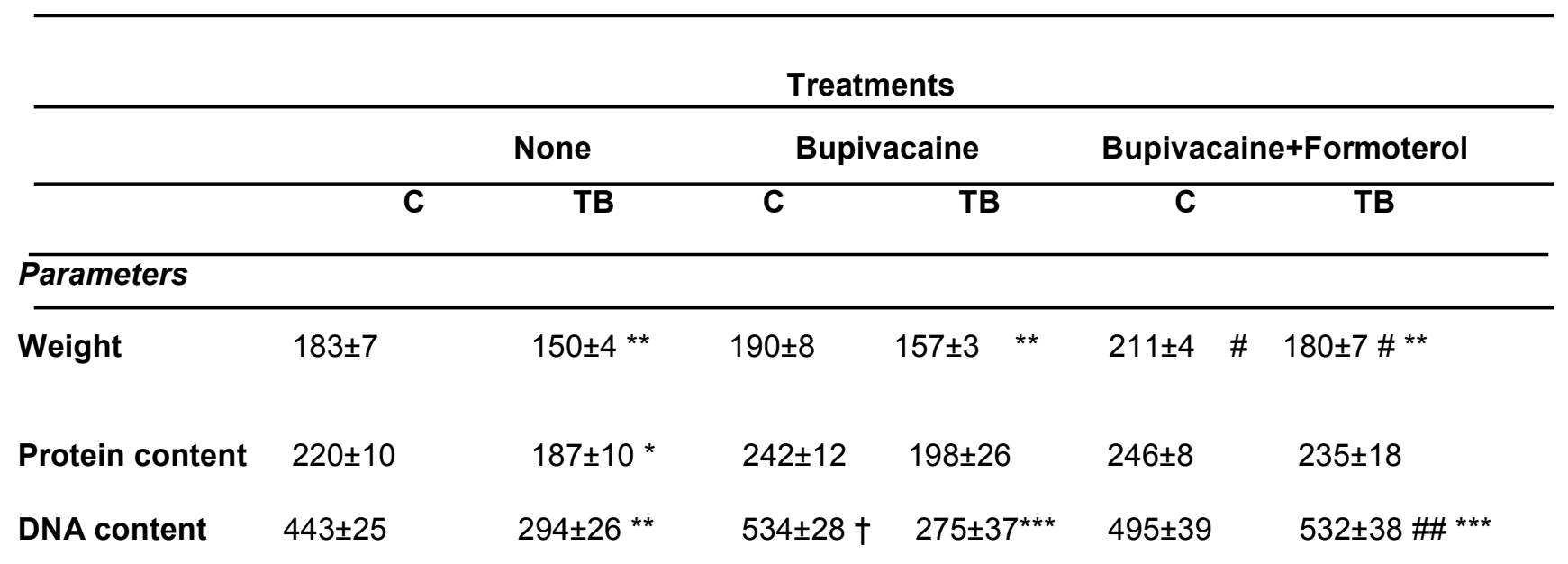

\section{Markers}

mRNA

$\begin{array}{lcccccc}\text { Pax-7 } & 100 \pm 14 & 47 \pm 18^{*} & 139 \pm 10 \dagger & 5 \pm 1 \dagger^{* * *} & 240 \pm 18 \# \# & 61 \pm 12 \# \# \# \text { *** } \\ \text { MyoD } & 100 \pm 12 & 67 \pm 1^{*} & 125 \pm 9 & 62 \pm 6^{* * *} & 136 \pm 4 & 58 \pm 2^{* * *} \\ & & & & & & \\ \text { Myogenin } & 100 \pm 12 & 78 \pm 17 & 233 \pm 29+\dagger & 74 \pm 18^{* * *} & 75 \pm 6 \# \# & 47 \pm 14\end{array}$

\section{Protein}

\begin{tabular}{lcccccc} 
MyoD & $100 \pm 17$ & $93 \pm 4$ & $102 \pm 16$ & $81 \pm 9$ & $113 \pm 12$ & $97 \pm 15$ \\
Cyclin D & $100 \pm 14$ & $97 \pm 3$ & $51 \pm 5(5) \dagger$ & $58 \pm 5+\dagger \dagger$ & $44 \pm 9$ & $28 \pm 1 \# \# \#$ \\
Calcineurin & $100 \pm 27$ & $54 \pm 21$ & $163 \pm 34(5)$ & $20 \pm 3 * *$ & $180 \pm 22$ & $76 \pm 27 \#$ * \\
\hline
\end{tabular}

For more details see the Material and Methods section. Results are mean \pm S.E.M. for 6 animals. The weight of the tibialis is expressed in $\mathrm{mg} / 100 \mathrm{~g}$ of initial weight of rats. The protein content is expressed in $\mathrm{mg}$ protein/g tibialis. The DNA content is expressed in $\mathrm{ng} / \mathrm{ml}$ The data (densitometric units) of both markers as protein and mRNA are represented as the percentage compared to control group (non-treated animal) C: control, TB: tumour-bearing animals. Values that are significantly different by the Student's t-test from the control group are indicated by $* \mathrm{p}<0.05, * * \mathrm{p}<0.01, * * * \mathrm{p}<0.001$. Values that are significantly different by the Student's t-test from the bupivacaine-treated group are indicated by $\dagger p<0.05, \dagger \dagger p<0.01, \uparrow \dagger \dagger p<0.001$. Values that are 
significantly different by the Student's t-test between the bupivacaine-treated group and the formoterol+bupivacaine-treated goup are indicated by $\# \mathrm{p}<0.05$, \#\# $\mathrm{p}<0.01$, \#\#\# $\mathrm{p}<0.001$.

\section{Experimental Section}

\subsection{Animals}

Male Wistar rats (Interfauna, Barcelona, Spain) of 5 weeks of age were used in the different experiments. The animals were maintained at $22 \pm 2{ }^{\circ} \mathrm{C}$ with a regular light-dark cycle (light on from 08:00 a.m. to 08:00 p.m.) and had free access to food and water. The food intake was measured daily. All animal manipulations were made in accordance with the European Community guidelines for the use of laboratory animals.

\subsection{Tumour inoculation and formoterol treatment}

Rats were divided into two groups, namely controls and tumour hosts. The latter received an intraperitoneal inoculum of $10^{8} \mathrm{AH}-130$ Yoshida ascites hepatoma cells obtained from exponential tumours ${ }^{43}$. Both groups were further divided into treated and untreated, the former being administered a daily subcutaneous (s.c.) dose of formoterol $(0.3 \mathrm{mg} / \mathrm{kg}$ body weight (bw), dissolved in physiological solution), and the latter the corresponding volume of solvent. On day 7 after tumour transplantation, the animals were weighed and anaesthetized with an i.p. injection of ketamine/xylazine mixture (3:1) (Imalgene $^{\circledR}$ and Rompun ${ }^{\circledR}$ respectively). The tumour was harvested from the peritoneal cavity and its volume and cellularity evaluated. Tissues were rapidly excised, weighed, and frozen in liquid nitrogen.

\subsection{Bupivacaine treatment}

Rats were divided into two groups, namely controls and bupivacaine-treated animals. Bupivacaine group were administered to the tibialis muscle with an acute and local dose of bupivacaine $(100 \mu \mathrm{L}$ of $0,5 \%$ bupivacaine hydrochloride (Sigma) dissolved in $0,9 \% \mathrm{NaCl}$ solution) ${ }^{44}$ and control group with the corresponding volume of solvent. One group of rats was sacrificed at 7 days after administration of bupivacaine, and other group was sacrificed after 14 days. On days 7 and 14 after bupivacaine treatment the animals were weighed and anaesthetized with an i.p. injection of ketamine/xylazine mixture (3:1) (Imalgene ${ }^{\circledR}$ and Rompun ${ }^{\circledR}$ respectively). Tissues were rapidly excised, weighed, and frozen in liquid nitrogen.

\subsection{Tumour-bearing animals treated with bupivacaine and formoterol}

Rats were divided into two groups, namely controls and tumour hosts. Both groups were further divided into treated and untreated, the former being administered to the tibialis muscle with an acute and local dose of bupivacaine $(100 \mu \mathrm{L}$ of $0,5 \%$ bupivacaine hydrochloride (Sigma) dissolved in $0,9 \% \mathrm{NaCl}$ solution) ${ }^{44}$ and the latter with the corresponding volume of solvent. After 7 days of administration of bupivacaine the tumour group received an 
intraperitoneal inoculum of $10^{8} \mathrm{AH}-130$ Yoshida ascites hepatoma cells obtained from exponential tumours. The different groups (controls and tumour hosts) were further divided into treated ( 7 days after the administration of bupivacaine) and untreated, the former being administered a daily subcutaneous (s.c.) dose of formoterol $(0.3 \mathrm{mg} / \mathrm{kg}$ body weight (bw), dissolved in physiological solution) and the latter a corresponding volume of solvent. On day 7 after tumour transplantation all the animals were sacrificed. All the animals were weighed and anaesthetized with an i.p. injection of ketamine/xylazine mixture $(3: 1)$ (Imalgene ${ }^{\circledR}$ and Rompun ${ }^{\circledR}$ respectively) for the sacrificed. Tissues were rapidly excised, weighed, and frozen in liquid nitrogen.

\subsection{Cell cultures}

C2C12 mouse skeletal muscle cells were obtained from the American Type Culture Collection (ATCC ${ }^{\circledR}$ Number: CRL-1772 ${ }^{\mathrm{TM}}$ ). Cells were passaged in high-glucose Dulbecco's modified Eagle's medium (DMEM) supplemented with 10\% fetal bovine serum (FBS), 100 $\mathrm{U} / \mathrm{mL}$ penicillin, $100 \mu \mathrm{g} / \mathrm{mL}$ streptomycin, $25 \mathrm{ng} / \mathrm{mL}$ fungizone, $110 \mu \mathrm{g} / \mathrm{mL}$ sodium pyruvate, and $2 \mathrm{mM}$ L-glutamine, in a humidified atmosphere of $5 \% \mathrm{CO}_{2}$ and $95 \%$ air at $37{ }^{\circ} \mathrm{C}$. For experimental analysis, cells were seeded at $3.7 \times 10^{4}$ cells $/ \mathrm{cm}^{2}$ in $10 \% \mathrm{FBS} / \mathrm{DMEM}$ until they reached $90-100 \%$ confluence 24 hours later. At this time, the medium was replaced by DMEM containing $10 \%$ horse serum for induction of differentiation for genetically modified cells. Abundant myotube formation, monitored microscopically, occurred after 4 days in $10 \%$ horse serum (HS)/DMEM. Such fused myotube cultures were treated with $0.1 \mu \mathrm{M}$ of formoterol during 3 days.

\subsection{Proliferation assay}

C2C12 cells were seeded in multiwells plates and cultured for 24 hours for cell attachment. Then, the cells were serum-starved for 24 hours more and treated with $0.1 \mu \mathrm{M}$ of formoterol or vehicle solution depending on the experimental group. After 24 hours of treatment, $1 \mu \mathrm{Ci}$ of methyl- $\left[{ }^{3} \mathrm{H}\right]$ thymidine (Amersham, Spain) was added to each well, and cells were incubated for 24 hours more for thymidine incorporation into DNA ${ }^{45,46}$. To measure the cell proliferation rate, cells were washed twice with PBS, and DNA was precipitated using trichloroacetic acid. Finally, cells were homogenized and the total amount of lysate was dissolved in $4 \mathrm{~mL}$ of liquid-scintillation fluid for total radioactivity estimation in a liquid scintillation counter.

\subsection{DNA content assay}

DNA content quantification in muscle was performed by Hoeschst staining. Tissue were homogenised with the following buffer: $1 \mathrm{~N} \mathrm{NH} \mathrm{NH}_{4} \mathrm{OH}, 0.2 \%$ Triton $\mathrm{X}-100,1 \mathrm{~mL} / \mathrm{mL}$ of protease inhibitors cocktail (Sigma, Spain). The homogenate was incubated during 30 minutes at room temperature with the Hoechst dye $(0.1 \mathrm{mg} / \mathrm{mL}$ Hoechst NERs $10 \mathrm{X}(2 \mathrm{M} \mathrm{NaCl}, 6 \mathrm{mM}$ 
Tris, $1 \mathrm{mM}$ EDTA). Finally, DNA content was quantified with the fluorimeter Shimadzu RF 5001 PC.

\subsection{RNA isolation}

Total RNA from C2C12 cells was extracted by TriPureTM kit (Roche, Barcelona, Spain), a commercial modification of the acid guanidinium isothiocyanate/phenol/chloroform method 47.

\subsection{Real-time PCR (polymerase chain reaction)}

First-strand cDNA was synthesized from total RNA with oligo dT15 primers and random primers pdN6 by using a cDNA synthesis kit (Transcriptor Reverse Transcriptase, Roche, Barcelona, Spain). Analysis of mRNA levels for PAX7, MyoD, myogenin and 18S was performed with primers designed to detect these products: Pax7: UP:GGAAAACCAGTGTGCCATCT DO:CCTTGTCTTTGGCACCATTT; MyoD: UP:CGACTGCTTTCTTCACCACA, DO:CTCAACCCAAGCCTGAAGAG; Myogenin: UP:GTCTTTTCCGACCTGATGGA, DO:GTCCCCAGTCCCTTCTCTTC; TNF- $\alpha$ : UP:TACTGAACTTCGGGGTGATTGGTC, DO:AGCCTTGTCCCTTGAAGAGAACC and 18S: UP:CGCAGAATTCCCACTCCCGACCC DO:CCCAAGCTCCAACTACGAGC. To avoid the detection of possible contamination by genomic DNA, primers were designed in different exons. The real-time PCR was performed using a commercial kit (LightCycler ${ }^{\mathrm{TM}}$ FastStart DNA Master ${ }^{\text {PLUS }}$ SYBR Green I, Roche, Barcelona, Spain). The relative amount of all mRNA was calculated using comparative $\mathrm{C}_{\mathrm{T}}$ method. $18 \mathrm{~S}$ mRNA was used as the invariant control for all studies.

\subsection{Western Blot}

Cell culture were homogenized in $10 \mathrm{mmol} / \mathrm{L}$ HEPES (pH 7.5), $10 \mathrm{mmol} / \mathrm{L} \mathrm{MgCl}_{2}, 5$ $\mathrm{mmol} / \mathrm{L} \mathrm{KCl}, 0.1 \mathrm{mmol} / \mathrm{L}$ EDTA, $0.1 \%$ Triton X-100, $1 \mathrm{mmol} / \mathrm{L}$ DTT, and $5 \mu \mathrm{L} / \mathrm{mL}$ of buffer of a protease inhibitor cocktail (Sigma, Spain). Cell homogenates were then centrifuged at 7,000 rpm for $5 \mathrm{~min}$ at $4^{\circ} \mathrm{C}$, and the supernatants were collected. Protein concentrations were determined according to the method of bicinchoninic acid (Pierce, Spain). Equal amounts of protein $(50$ or $100 \mu \mathrm{g})$ were heat denatured in sample loading buffer [50 mmol/L Tris-HCl (pH 6.8), $100 \mathrm{mmol} / \mathrm{L}$ DTT, 2\% SDS, 0.1\% bromophenol blue, 10\% glycerol], resolved by SDS-PAGE (10\% polyacrylamide, $0.1 \%$ SDS), and transferred to Immobilon membranes (Immobilon polyvinylidene difluoride, Millipore). The filters were blocked with 5\% PBSnonfat dry milk and then incubated with polyclonal antibodies: anti-cyclin D1 (Santa Cruz Biotecnology), anti-Calcineurin (Sigma, Spain), and anti-MyoD (Santa Cruz Biotecnology) Polyclonal antibody anti-GAPDH (Sigma, Spain) was used as the invariant control for the different studies. Donkey anti-mouse peroxidase-conjugated IgG (Jackson ImmunoResearch, Laboratories, Inc.), rabbit anti-goat peroxidase-conjugated IgG (Acris Antibodies GmbH), and goat anti-rabbit horseradish peroxidase conjugate (Bio-Rad) were used as secondary 
antibodies. The membrane-bound immune complexes were detected by an enhanced chemioluminescence system (EZ-ECL, Amersham Biosciences).

\subsection{Biochemicals}

They were all reagent grade and obtained either from Roche S.A. (Barcelona, Spain) or from Sigma Chemical Co. (St. Louis, MO, USA). Radiochemicals were purchased from Amersham Int. (Amersham, Bucks., UK). Formoterol fumarate micronized was kindly provided by Industriale Chimica s.r.l. (Saronno, Italy).

\subsection{Statistical analysis}

Statistical analysis of the data was performed by means of the Student's t test.

\section{Conclusions}

The results presented here show that the regeneration mechanisms in tumour-bearing animals, and also in bupivacaine-treated animals (where the process of regeneration is induced) are blocked. Increased DNA observed in the groups treated with formoterol in conjunction with the results of the analysis of molecular markers involved in regeneration, suggest that formoterol is capable of activating the regeneration mechanisms which are blocked in cancer cachexia. This is probably due to the fact that formoterol is able to block the action of TNF- $\alpha$ in skeletal muscle (a cytokine which has high plasma levels in animals carrying different types of cachexia-inducing tumours) (muscle mRNA content for TNF- $\alpha$ (\% of control): control group: $100 \pm 23$ (4), formoterol-treated group: $97 \pm 3$ (4); tumourbearing group: $185 \pm 15$ (4) $\mathrm{p}<0.05$ vs control group ; formoterol-treated tumour-bearing group: $115 \pm 9(4) \dagger \uparrow p<0.01$ vs tumour). Results obtained by other authors suggest that TNF blocks acquired myogenic differentiation in vitro ${ }^{48-50}$ and in vivo ${ }^{48}$ and it is not necessary for muscle regeneration 51,52 .

Altogether, the data presented here point towards a new role for formoterol at the skeletal muscle level. While previous studies have clearly shown the benefit of the $\beta 2$-agonist in muscle wasting conditions such as cancer cachexia ${ }^{17}$ and muscle atrophy ${ }^{53}$ by decreasing protein degradation, the present contribution puts forward the idea that formoterol facilitates muscle regeneration. This observation, together with the antiapoptotic properties of the $\beta 2$ agonist ${ }^{17}$, suggest that the molecule may be an excellent drug for the treatment of muscle wasting, alone or in combination with other anabolic drugs.

\section{Acknowledgements}

Elisabet Ametller was supported from the Instituto de Salud Carlos III (03/0100). Gemma Fuster was supported from the Dirección General de Investigación Científica y Técnica (BFI2002-02186) of the Ministerio de Educación y Ciencia. Cibely Oliveira was supported by the Programme Alßan, the European Union Programme of High Level Scholarships for Latin America, scholarship no. E05D059293BR. Contract grant sponsors: Instituto de Salud Carlos 
III of the Ministerio de Sanidad y Consumo (06/0907); Ministerio de Ciencia y Tecnología (SAF 4744-2005); Ministerio de Ciencia y Tecnología (SAF-02284-2008) and Generalitat de Catalunya (SGR/00108). The authors would like to thank Industriale Chimica s.r.l. (Saronno, Italy), which kindly provided formoterol fumarate micronized.

\section{References and Notes}

1. Warren, S. The immediate causes of death in cancer. Am J Med Sci 1932, 184, 610-615.

2. Argiles, J. M.; Alvarez, B.; Lopez-Soriano, F. J. The metabolic basis of cancer cachexia. Med Res Rev 1997, 17, 477-98.

3. Harvey, K. B.; Bothe, A., Jr.; Blackburn, G. L. Nutritional assessment and patient outcome during oncological therapy. Cancer 1979, 43, 2065-9.

4. Nixon, D. W.; Heymsfield, S. B.; Cohen, A. E.; Kutner, M. H.; Ansley, J.; Lawson, D. H.; Rudman, D. Protein-calorie undernutrition in hospitalized cancer patients. Am J Med 1980, 68, 683-90.

5. DeWys, W. Management of cancer cachexia. Semin Oncol 1985, 12, 452-60.

6. Argiles, J. M.; Garcia-Martinez, C.; Llovera, M.; Lopez-Soriano, F. J. The role of cytokines in muscle wasting: its relation with cancer cachexia. Med Res Rev 1992, 12, 637-52.

7. van Royen, M.; Carbo, N.; Busquets, S.; Alvarez, B.; Quinn, L. S.; Lopez-Soriano, F. J.; Argiles, J. M. DNA fragmentation occurs in skeletal muscle during tumor growth: A link with cancer cachexia? Biochem Biophys Res Commun 2000, 270, 533-7.

8. Stock, M. J.; Rothwell, N. J., Effects of $\beta$-adrenergic agonists on metabolism and body composition. . In Control and manipulation of Animal Growth. , Buttery, P. J.; Hayes, N. B.; Lindsay, D. B., Eds. Butterworths, London, 1985; pp 249-257.

9. Kim, Y. S.; Sainz, R. D. Beta-adrenergic agonists and hypertrophy of skeletal muscles. Life Sci 1992, 50, 397-407.

10. Agbenyega, E. T.; Wareham, A. C. Effect of clenbuterol on skeletal muscle atrophy in mice induced by the glucocorticoid dexamethasone. Comp Biochem Physiol Comp Physiol 1992, 102, 141-5.

11. Rajab, P.; Fox, J.; Riaz, S.; Tomlinson, D.; Ball, D.; Greenhaff, P. L. Skeletal muscle myosin heavy chain isoforms and energy metabolism after clenbuterol treatment in the rat. Am J Physiol Regul Integr Comp Physiol 2000, 279, R1076-81.

12. Hinkle, R. T.; Hodge, K. M.; Cody, D. B.; Sheldon, R. J.; Kobilka, B. K.; Isfort, R. J. Skeletal muscle hypertrophy and anti-atrophy effects of clenbuterol are mediated by the beta2-adrenergic receptor. Muscle Nerve 2002, 25, 729-34.

13. Wineski, L. E.; von Deutsch, D. A.; Abukhalaf, I. K.; Pitts, S. A.; Potter, D. E.; Paulsen, D. F. Muscle-specific effects of hindlimb suspension and clenbuterol in mature male rats. Cells Tissues Organs 2002, 171, 188-98.

14. Yang, Y. T.; McElligott, M. A. Multiple actions of beta-adrenergic agonists on skeletal muscle and adipose tissue. Biochem J 1989, 261, 1-10. 
15. Mersmann, H. J. Overview of the effects of beta-adrenergic receptor agonists on animal growth including mechanisms of action. J Anim Sci 1998, 76, 160-72.

16. Carbo, N.; Lopez-Soriano, J.; Tarrago, T.; Gonzalez, O.; Llovera, M.; Lopez-Soriano, F. J.; Argiles, J. M. Comparative effects of beta2-adrenergic agonists on muscle waste associated with tumour growth. Cancer Lett 1997, 115, 113-8.

17. Busquets, S.; Figueras, M. T.; Fuster, G.; Almendro, V.; Moore-Carrasco, R.; Ametller, E.; Argiles, J. M.; Lopez-Soriano, F. J. Anticachectic effects of formoterol: a drug for potential treatment of muscle wasting. Cancer Res 2004, 64, 6725-31.

18. Anderson, G. P. Pharmacology of formoterol: an innovative bronchodilator. Agents Actions Suppl 1991, 34, 97-115.

19. Mahler, D. A. The effect of inhaled beta2-agonists on clinical outcomes in chronic obstructive pulmonary disease. J Allergy Clin Immunol 2002, 110, S298-303.

20. Luz, M. A.; Marques, M. J.; Santo Neto, H. Impaired regeneration of dystrophindeficient muscle fibers is caused by exhaustion of myogenic cells. Braz J Med Biol Res 2002, 35, 691-5.

21. Seale, P.; Sabourin, L. A.; Girgis-Gabardo, A.; Mansouri, A.; Gruss, P.; Rudnicki, M. A. Pax7 is required for the specification of myogenic satellite cells. Cell 2000, 102, 777-86.

22. Schultz, E.; Gibson, M. C.; Champion, T. Satellite cells are mitotically quiescent in mature mouse muscle: an EM and radioautographic study. $J$ Exp Zool 1978, 206, 451-6.

23. Schultz, E.; McCormick, K. M. Skeletal muscle satellite cells. Rev Physiol Biochem Pharmacol 1994, 123, 213-57.

24. Goetsch, S. C.; Hawke, T. J.; Gallardo, T. D.; Richardson, J. A.; Garry, D. J. Transcriptional profiling and regulation of the extracellular matrix during muscle regeneration. Physiol Genomics 2003, 14, 261-71.

25. Ryall, J. G.; Schertzer, J. D.; Alabakis, T. M.; Gehrig, S. M.; Plant, D. R.; Lynch, G. S. Intramuscular beta2-agonist administration enhances early regeneration and functional repair in rat skeletal muscle after myotoxic injury. J Appl Physiol 2008, 105, 165-72.

26. Shi, X.; Garry, D. J. Muscle stem cells in development, regeneration, and disease. Genes Dev 2006, 20, 1692-708.

27. Roberts, P.; McGeachie, J. K. The enhancement of revascularisation of skeletal muscle transplants using the beta 2-agonist isoprenaline. J Anat 1994, 184 ( Pt 2), 309-18.

28. Grounds, M. D.; Yablonka-Reuveni, Z. Molecular and cell biology of skeletal muscle regeneration. Mol Cell Biol Hum Dis Ser 1993, 3, 210-56.

29. Roberts, P.; McGeachie, J. K. The effects of clenbuterol on satellite cell activation and the regeneration of skeletal muscle: an autoradiographic and morphometric study of whole muscle transplants in mice. J Anat 1992, 180 ( Pt 1), 57-65.

30. Lynch, G. S.; Schertzer, J. D.; Ryall, J. G. Anabolic agents for improving muscle regeneration and function after injury. Clin Exp Pharmacol Physiol 2008, 35, 852-8.

31. Ryall, J. G.; Church, J. E.; Lynch, G. S. Novel role for beta-adrenergic signalling in skeletal muscle growth, development and regeneration. Clin Exp Pharmacol Physiol 37, 397-401. 
32. Beitzel, F.; Sillence, M. N.; Lynch, G. S. beta-Adrenoceptor signaling in regenerating skeletal muscle after beta-agonist administration. Am J Physiol Endocrinol Metab 2007, 293, E932-40.

33. Hall-Craggs, E. C. Rapid degeneration and regeneration of a whole skeletal muscle following treatment with bupivacaine (Marcain). Exp Neurol 1974, 43, 349-58.

34. Zammit, P. S.; Golding, J. P.; Nagata, Y.; Hudon, V.; Partridge, T. A.; Beauchamp, J. R. Muscle satellite cells adopt divergent fates: a mechanism for self-renewal? J Cell Biol 2004, 166, 347-57.

35. Yablonka-Reuveni, Z.; Rivera, A. J. Temporal expression of regulatory and structural muscle proteins during myogenesis of satellite cells on isolated adult rat fibers. Dev Biol 1994, 164, 588-603.

36. Nagata, Y.; Kobayashi, H.; Umeda, M.; Ohta, N.; Kawashima, S.; Zammit, P. S.; Matsuda, R. Sphingomyelin levels in the plasma membrane correlate with the activation state of muscle satellite cells. J Histochem Cytochem 2006, 54, 375-84.

37. Friday, B. B.; Horsley, V.; Pavlath, G. K. Calcineurin activity is required for the initiation of skeletal muscle differentiation. $J$ Cell Biol 2000, 149, 657-66.

38. Grant, A. L.; Helferich, W. G.; Merkel, R. A.; Bergen, W. G. Effects of phenethanolamines and propranolol on the proliferation of cultured chick breast muscle satellite cells. J Anim Sci 1990, 68, 652-8.

39. Foster, A. H.; Carlson, B. M. Myotoxicity of local anesthetics and regeneration of the damaged muscle fibers. Anesth Analg 1980, 59, 727-36.

40. Bradley, W. G., Muscle fiber splitting. In Muscle Regeneration Mauro, A., Ed. 1979; pp 215-232.

41. Orimo, S.; Hiyamuta, E.; Arahata, K.; Sugita, H. Analysis of inflammatory cells and complement C3 in bupivacaine-induced myonecrosis. Muscle Nerve 1991, 14, 515-20.

42. Rosenblatt, J. D.; Woods, R. I. Hypertrophy of rat extensor digitorum longus muscle injected with bupivacaine. A sequential histochemical, immunohistochemical, histological and morphometric study. J Anat 1992, 181 ( Pt 1), 11-27.

43. Tessitore, L.; Costelli, P.; Bonetti, G.; Baccino, F. M. Cancer cachexia, malnutrition, and tissue protein turnover in experimental animals. Arch Biochem Biophys 1993, 306, 52-8.

44. Politi, P. K.; Havaki, S.; Manta, P.; Lyritis, G. Bupivacaine-induced regeneration of rat soleus muscle: ultrastructural and immunohistochemical aspects. Ultrastruct Pathol 2006, 30, 461-9.

45. Vitt, U. A.; Mazerbourg, S.; Klein, C.; Hsueh, A. J. Bone morphogenetic protein receptor type II is a receptor for growth differentiation factor-9. Biol Reprod 2002, 67, 473-80.

46. Spicer, L. J.; Aad, P. Y.; Allen, D. T.; Mazerbourg, S.; Payne, A. H.; Hsueh, A. J. Growth differentiation factor 9 (GDF9) stimulates proliferation and inhibits steroidogenesis by bovine theca cells: influence of follicle size on responses to GDF9. Biol Reprod 2008, 78, 243-53.

47. Chomczynski, P.; Sacchi, N. Single-step method of RNA isolation by acid guanidinium thiocyanate-phenol-chloroform extraction. . Anal Biochem 1987, 162, 156-159. 
48. Coletti, D.; Yang, E.; Marazzi, G.; Sassoon, D. TNFalpha inhibits skeletal myogenesis through a PW1-dependent pathway by recruitment of caspase pathways. EMBO J 2002, $21,631-42$.

49. Guttridge, D. C.; Mayo, M. W.; Madrid, L. V.; Wang, C. Y.; Baldwin, A. S., Jr. NFkappaB-induced loss of MyoD messenger RNA: possible role in muscle decay and cachexia. Science 2000, 289, 2363-6.

50. Ladner, K. J.; Caligiuri, M. A.; Guttridge, D. C. Tumor necrosis factor-regulated biphasic activation of NF-kappa B is required for cytokine-induced loss of skeletal muscle gene products. J Biol Chem 2003, 278, 2294-303.

51. Collins, R. A.; Grounds, M. D. The role of tumor necrosis factor-alpha (TNF-alpha) in skeletal muscle regeneration. Studies in TNF-alpha(-/-) and TNF-alpha(-/-)/LT-alpha(-/-) mice. J Histochem Cytochem 2001, 49, 989-1001.

52. Grounds, M. D.; McGeachie, J. K. A comparison of muscle precursor replication in crush-injured skeletal muscle of Swiss and BALBc mice. Cell Tissue Res 1989, 255, 38591.

53. Katoch, S. S.; Garg, A.; Sharma, S. Histological evidences of reparative and regenerative effects of beta-adrenoceptor agonists, clenbuterol and isoproterenol, in denervated rat skeletal muscle. Indian J Exp Biol 2006, 44, 448-58.

(C) 2011 by the Authors; License Insciences Journal.

Open Access article under the terms and conditions of Creative Commons Attribution Non-Commercial License 3.0 Unported. 